\title{
Estado da arte sobre a formação de professores entre 2001 e 2016: um olhar sobre a produção brasileira a partir do Portal de periódicos CAPES/MEC
}

\section{State of the art about teacher training between 2001 and 2016: a look at Brazilian production from Portal of periodicals of CAPES/MEC}

\section{Estado del arte sobre formación de profesores entre 2001 y 2016: una mirada sobre la producción brasileña a partir del Portal de periódicos CAPES/MEC}

\author{
Jerry Adriano Raimundo' \\ Município de Curitiba, PR, Professor do Ensino Fundamental
}

Maurício Cesar Uitória Fagundes²

Universidade Federal do Paraná, Professor de Ensino Superior, possui experiência na área de Educação, com ênfase na Formação de Professores e Gestão em Educação Básica e

Educação Superior

Resumo: Neste artigo coloca-se em tela o estado da arte das pesquisas brasileiras sobre a formação de professores dos primeiros 15 anos do século XXI. Tem-se por objetivo questionar a quantidade, a frequência, a autoria, as origens das pesquisas e as suas correlações. Neste trabalho aponta-se a progressão do estudo desse tema, caracterizam-se e organizam-se informações para servir de base investigativa para outras pesquisas. Para isso, foram coletados os dados do Portal de periódicos da CAPES/MEC, utilizando o método estatístico para mapear as produções desse período. A pesquisa é de natureza quantitativa e descreve a categorização dos dados a fim de apontar o desencadeamento do tema no primeiro quindênio do presente século. Os resultados apontam lacunas de assuntos e decréscimo da frequência e quantidade de pesquisas sobre a formação de professores nesse período. Esta pesquisa teve como

Mestre em Educação pela Universidade Federal do Paraná; Especialista em Filosofia Contemporânea pela Faculdade de Administração, Ciências, Educação e Letras.

2 Doutor em Educação pela Universidade do Vale do Rio dos Sinos; Mestre em Educação pela Universidade Federal de Pelotas. 
principais interlocutores: Romanowski e Ens (2006), André (2002), Brzezinski (2006, 2014), Gil (2008) e Ferreira (2002).

Palavras-chave: Formação de professores. Pesquisa. Estado da arte.

Abstract: This paper presents the developments of Brazilian research on the education of teachers during the first 15 years of the twenty-first century. It inquires and correlates the output, frequency, authorship and origins of such researches. This work points to a continuous development on the field, and organizes data for future research. To this end, it collects the bibliographical data from Portal of periodicals of CAPES/MEC, using statistical methods to analyze the information. A quantitative approach is used to describe the data and its categories, to show the developments on the field over the period. Results show a lack of research on some subjects and a diminishing in both frequency and total output of research on teacher's education. This research had as main interlocutors: Romanowski and Ens (2006), André (2002), Brzezinski (2006, 2014), Gil (2008) and Ferreira (2002).

Keywords: Teachers qualification. Research. State-of-the-art.

Resumen: El artículo pone en pantalla el estado del arte de las investigaciones brasileñas sobre la formación de profesores de los primeros 15 años del siglo XXI. Tiene por objetivo cuestionar la cantidad, la frecuencia, la autoría, los orígenes de las investigaciones y sus correlaciones. Este trabajo apunta a la progresión del estudio de este tema, caracteriza y organiza informaciones para servir de base investigativa para otras investigaciones. Para ello, recoge los datos bibliográficamente, oriundos del Portal de periódicos CAPES/MEC, utilizando el método estadístico para mapear las producciones de este período. La investigación es de naturaleza cuantitativa y describe la categorización de los datos a fin de apuntar el desencadenamiento del tema en el primer quindio del siglo. Los resultados apuntan lagunas de asuntos y decrecimiento de la frecuencia y cantidad en la investigación de la formación de profesores en este período. Esta investigación tuvo como principales interlocutores: Romanowski y Ens (2006), André (2002), Brzezinski (2006, 2014), Gil (2008) y Ferreira (2002).

Palabras clave: Formación de profesores. Investigación. Estado del arte. 


\section{INTRODUÇÃO}

A finalização do ano 2016 marcou o conjunto dos primeiros 15 anos do século XXI, momento oportuno para questionar o que se tem publicado acerca da formação docente a partir do produto de pesquisas das universidades e destacar como estas foram elaboradas no começo desse século.

Embora não seja a fonte de coleta dos dados e nem a especificidade da pesquisa que originou este artigo, entendemos ser significativo iniciar este texto colocando alguns dados apresentados pelo censo do ano 2001 ao ano 2016, produzidos pelo CNPq/Plataforma Diretório dos Grupos de Pesquisa no Brasil Lattes (DIRETÓRIOS DOS GRUPOS DE PESQUISA NO BRASIL, 2017), acerca do número de produções nas distintas áreas do conhecimento. Nesses números publicados e apresentados aqui de forma sucinta, sem entrar no mérito das causas, contextos que os originaram ou os influenciaram, registra-se um significativo crescimento do número de produções em artigos científicos nacionais e internacionais, livros, capítulos de livros, anais, produções técnicas, pesquisadores, grupos de pesquisas e formações em mestrados e doutorados.

Com base nos dados dispostos nessa Plataforma é possível verificar saltos quantitativos muito significativos, como o número de pesquisadores, que, no primeiro censo de 2012, na área da Educação, era de 4.518 e avançou para 26.011 em 2016. O número dos grupos de pesquisa, que em 2002 era de 899, passou para 3.595 em 2016. O Estado com maior número de pesquisadores, englobando todas as áreas, é São Paulo, que em 2002 tinha 16.789 e em 2016 passou para 45.204; nessa mesma categoria o Estado com menor número de pesquisadores em 2002 era o Amapá, com 37, e em 2016 era o Estado de Roraima, com 775. O número de produções em artigos completos de circulação nacional, na grande área das Ciências Humanas, que em 2002 era de 12.701, passou, em 2016, para 72.210. Ainda na grande área das Ciências Humanas, os artigos completos de circulação internacional, que em 2012 eram de 2.250, passaram para 18.293; os trabalhos completos publicados em anais de eventos 
saltam de 10.730 para 61.625 em 2016; as teses de 1.918 e dissertações de 8.523 em 2012 para 9.753 e 33.240, respectivamente.

Esses dados ilustram, de forma geral, o crescimento numérico das produções brasileiras, publicadas no sítio do CNPq/Grupos de Pesquisa. Porém, neste artigo queremos resgatar, quantitativamente, a recente história que marca os 15 anos iniciais do século XXI, por meio de pesquisas no Portal de periódicos da CAPES/MEC, elegendo artigos de uma temática mais específica dentro da área da Educação, apresentando a investigação sobre a formação de professores ou formação docente, aqui abordadas como sinônimas. Além de objetivar a compreensão dos principais movimentos da pesquisa sobre a formação de professores, colocamos em tela também: os assuntos recorrentes que emergem dessa temática; as universidades e a representação geográfica de suas localizações; e as revistas e autores que aparecem com maior representatividade nesse período pesquisado.

Essa sistematização, fruto de um amplo apanhado de variáveis de um determinado tema em relação a dado período de tempo, é o estado da arte, que neste artigo procura compreender a progressão do tema em sua totalidade. Segundo Romanowski e Ens (2006, p. 41), colocar em evidência essa temática se justifica porque possibilita "uma visão geral do que vem sendo produzido na área e uma ordenação que permite aos interessados perceberem a evolução das pesquisas na área, bem como suas características e foco, além de identificar as lacunas ainda existentes."

Antes de adentrar na proposta principal deste artigo, faremos uma breve retomada do estado da arte dessa temática, formação de professores, já sistematizada e publicada por meio de três amplas pesquisas coordenadas pela Associação Nacional de Pós-Graduação e Pesquisa em Educação (ANPEd) e publicadas pelo Instituto Nacional de Estudos e Pesquisas Educacionais Anísio Teixeira (Inep).

A primeira pesquisa, organizada pela Professora Doutora Marli Eliza Dalmazo Afonso de André, consistiu no mapeamento da produção científica na área de formação de professores, na obra com o título Formação de professores no Brasil (1990-1998), publicada em 2002 pelo Inep. 
A segunda e a terceira pesquisas organizadas pela Professora Doutora Iria Brzezinski, sob o título Formação de profissionais da educação (1997-2002) e Formação de profissionais da educação (2003-2010), publicadas pelo Inep em 2006 e 2014, respectivamente, apresentam um balanço crítico de teses e dissertações desses períodos.

Portanto, assumimos aqui a ousadia do desejo de despertar outras pesquisas, oferecendo dados sistematizados que caracterizam as pesquisas desse tempo. Assim, a partir dos parâmetros a seguir anunciados na metodologia, o leitor encontra neste trabalho uma fonte de informações sobre o estado da arte da formação de professores no Brasil.

\section{ESTADO DA ARTE DA FORMAÇÃO DE PROFESSORES DE 1990 A 2010}

A temática formação de professores tem encontrado na Associação Nacional de Pós-Graduação e Pesquisa em Educação um espaço profícuo de discussão e problematização, reunindo produções de distintas regiões do Brasil e, por vezes, de fora do Brasil. Dos 23 Grupos de Trabalhos (GTs) que constituem a ANPEd, o GT 8 - Formação de Professores reúne educadores e pesquisadores desde o ano 1984. Na ocasião de sua constituição, nasceu como GT Licenciaturas, que sob a coordenação da professora Míriam Krasilchik, juntamente com seus pares, tinham como preocupação central a abordagem das questões da formação dos profissionais da educação. A transição para GT Formação de Professores ocorreu a partir de uma avaliação realizada na $16^{a}$ ANPEd, realizada em Caxambú em setembro de 1993, quando constatou-se que as pesquisas e processos desenvolvidos nas diversas Instituições de Ensino Superior (IES) e reveladas no então GT Licenciatura movimentavam-se "na busca pela articulação de estudos que envolviam a formação, o trabalho e a identidade docente. A partir da constatação da mudança na realidade no campo de pesquisa, decidiu-se pela modificação da denominação do GT, que passou a ser chamado de Formação de Professores." (ANPED, 2017). 
Com esse breve histórico fica visível a preocupação da pesquisa sobre a temática formação de professores. Nesse caminho, a ANPEd coordenou a realização de três amplas pesquisas publicadas pelo Instituto Nacional de Estudos e Pesquisas Educacionais Anísio Teixeira (Inep), que robustecem o estado da arte sobre a formação de professores da últibma década do século XX e da primeira década do século XXI, das quais apresentamos seus principais achados.

A pesquisa organizada pela Professora Dra. Marli Eliza Dalmazo Afonso de André, intitulada Formação de professores no Brasil (1990-1998), publicada em 2002 pelo Inep, priorizou como objetos de análise 115 artigos, em 10 periódicos nacionais; 284 dissertações e teses, produzidas nos programas de pós-graduação em educação, e 70 trabalhos, apresentados no GT Formação de professores da ANPEd no período de 1992-1998. Segundo André (2002, p. 13), a pesquisa

permitiu identificar uma significativa preocupação com o preparo do professor para atuar nas séries iniciais do ensino fundamental. Permitiu ainda evidenciar o silêncio quase total com relação à formação do professor para o ensino superior e para atuar na educação de jovens e adultos, no ensino técnico e rural, nos movimentos sociais e com crianças em situação de risco. Adicionalmente, permitiu verificar que são raros os trabalhos que focalizam o papel das tecnologias de comunicação, dos multimeios ou da informática no processo de formação; mais raros ainda são os que investigam o papel da escola no atendimento às diferenças e à diversidade cultural.

A autora afirma, ainda, que as análises das diversas fontes indicam um excesso de discurso sobre o tema formação docente e poucos dados empíricos que referenciem práticas e políticas educacionais.

Acerca da análise sobre os periódicos brasileiros, de 1990 a 1997. que também era foco dessa obra, resgatamos alguns dados de forma mais específica para uma análise comparativa com os achados deste artigo, que ora apresentamos, também sobre os periódicos brasileiros, porém dos que datam dos primeiros 15 anos deste século XXI. 
André (2002) explicita que o recorte de sua pesquisa pretendeu inventariar fontes, catalogação e classificação do material bibliográfico existente, categorização do material selecionado e análise do conteúdo. A partir desse recorte, analisou 115 artigos publicados em 10 periódicos, que são apresentados no Gráfico 1.

Gráfico l - Publicações por periódicos (1999-1997)

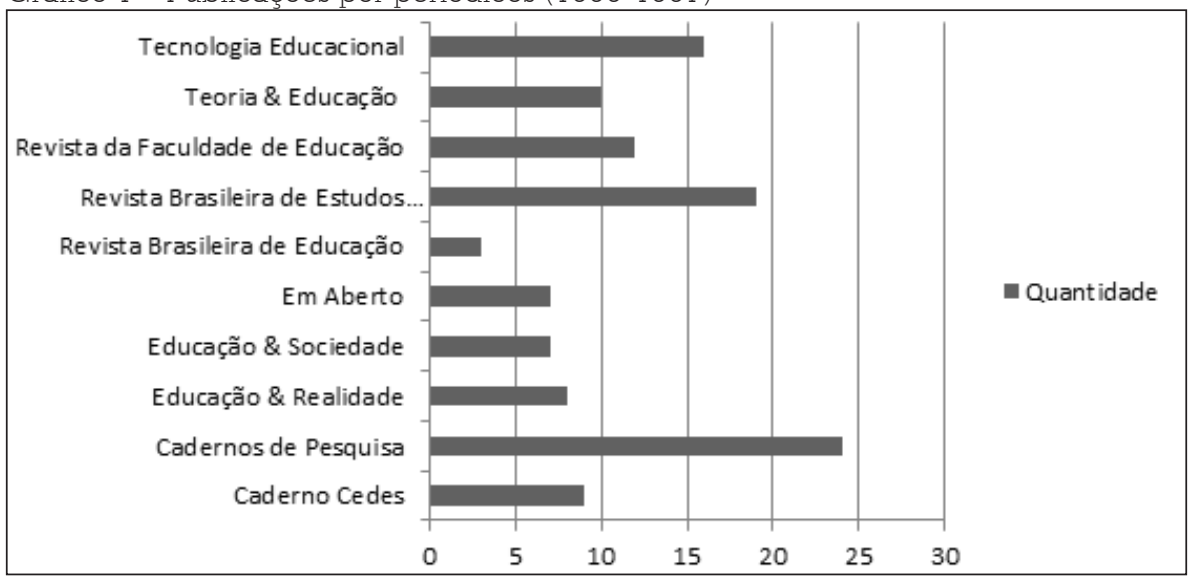

Fonte: adaptado pelos autores com base em André (2002).

As categorias temáticas recorrentes foram: Formação Continuada (30), Formação Inicial (27), Identidade e Profissionalização Docente (33) e Prática Pedagógica (25). A autora representa a distribuição das categorias temáticas e subtemas na Tabela l, que copiamos a seguir. 
Tabela 1 - Distribuição dos artigos por tema

\begin{tabular}{|c|c|c|}
\hline TEMAS & $\mathrm{N}^{\circ}$ & $\%$ \\
\hline Formação Inicial & 27 & 23,5 \\
\hline Escola Normal & 7 & 6,0 \\
\hline Cursos de Pedagogia & 6 & 5,5 \\
\hline Licenciaturas & 14 & 12,0 \\
\hline Formação Continuada & 30 & 26,0 \\
\hline Identidade e Profissionalização Docente & 33 & 28,7 \\
\hline Condições de Trabalho e Remuneração/Socialização & 14 & 12,2 \\
\hline Questão de Gênero & 11 & 9,6 \\
\hline Organização Política/Sindical & 5 & 4,3 \\
\hline Políticas Públicas Educacionais & 3 & 2,6 \\
\hline Prática Pedagógica & 25 & 22,0 \\
\hline Sala de Aula & 9 & 8,0 \\
\hline Prática Escolar & 11 & 9,5 \\
\hline Relações Escola-Sociedade & 5 & 4,5 \\
\hline TOTAL & 115 & 100,0 \\
\hline
\end{tabular}

Fonte: André (2002, p. 160).

A segunda pesquisa organizada pela Professora Doutora Iria Brzezinski, que consistiu no mapeamento da produção científica nas áreas de Formação de Profissionais da Educação, Currículo da Educação Básica e Educação e Tecnologia, envolveu três GTs da ANPEd: GT 8 - Formação de professores; GT 12 - Currículo e GT 16 - Educação e Comunicação, tendo como referência para a coleta de dados a produção científica discente de teses e dissertações defendidas no período de 1997-2002 em programas de pós-graduação em Educação credenciados pela Fundação Coordenação de Aperfeiçoamento de Pessoal de Nível Superior (CAPES) e Sócios Institucionais da ANPEd. Os resultados dessa pesquisa foram publicados na obra com o título Formação de profissionais da educação (1997-2002) em 2006 pelo Inep.

Essa pesquisa desenvolvida no período 1997-2002 levantou uma amostra de 742 trabalhos, entre teses e dissertações, oriundos de 50 programas de pós-graduação que trabalhavam com a temática Formação dos Profissionais da Educação no Brasil. Com relação às localizações dos programas ficou constatado que na região Sudeste havia 20 e na região Sul, 15 programas, 
seguidas das regiões Centro-Oeste e Nordeste, com sete cada uma, e Norte, com apenas um programa.

$\mathrm{Na}$ análise de conteúdo se configuraram sete grandes categorias (BRZEZINSKI, 2006), que são:
a) Concepções de Docência e de Formação de Professores;
b) Políticas e Propostas de Formação de Professores;
c) Formação Inicial;
d) Formação Continuada;
e) Trabalho Docente;
f) Identidade e Profissionalização Docente;
g) Revisão de Literatura.

Cada grande categoria anteriormente mencionada foi constituída por subcategorias, das quais destacamos as temáticas, que também se fizeram presentes na pesquisa que originou este artigo, quais sejam: fundamentos epistemológicos, filosóficos, sociológicos, antropológicos, históricos, psicológicos, didática, políticas de formação (educação a distância, Educação de Jovens e Adultos (EJA), curriculares, educação inclusiva, valorização da docência e profissionalização), história institucional, estágio supervisionado, avaliação, experiência, pesquisa, prática pedagógica, educação especial, trabalho docente, tecnologias, identidade, representações sociais, saberes, competências, inclusão, gênero e gestão.

Há temáticas que não encontramos nas categorias e nem nas subcategorias da pesquisa de Brzezinski (2006), mas se fazem presentes nos achados da pesquisa que origina este artigo, citamos: educação do campo, estética, história de vida, multiculturalismo, reflexão, subjetividade, autonomia, discurso, ética, filosofia da diferença, interculturalidade e paradigmas.

Em comparação com a primeira pesquisa Formação de professores no Brasil (1990-1998), de André (2002), a pesquisa de Brzezinski (2006) levanta e analisa um número maior de categorias, incorporando ao seu estudo: 
Concepções de Docência e de Formação de Professores, Políticas e Propostas de Formação de Professores e Revisão de Literatura e Trabalho docente.

Acerca da pesquisa organizada por Brzezinski (2006), cabe ressaltar que os dados aqui citados são desdobrados em uma multiplicidade de informações, em que não adentraremos neste artigo, mas convidamos os leitores a acessarem essa valiosa obra e aprofundarem a leitura.

A mesma autora publicou no ano 2014 outra pesquisa na área de Formação de Profissionais da Educação. Para tal, utilizou como referência para a coleta de dados: a produção científica discente, a análise de teses e dissertações defendidas no período de 2003-2007 e 2008-2010, sendo 574 no primeiro período e 200 no segundo. Foram teses e dissertações defendidas em 83 programas de pós-graduação em Educação credenciados pela CAPES e Sócios Institucionais da ANPEd. Os resultados dessa pesquisa foram publicados na obra Formação de profissionais da educação (2003-2010) em 2014 pelo Inep.

Brzezinski (2014, p. 12), ao principiar o texto de sua obra, chama a atenção para o "aumento substantivo dos programas recomendados pela CAPES, considerando que, em 1997 eram 50, em 2003 eram 61 e, em 2007, 83 programas." Acrescentamos que este número de 83 cresceu para 177 programas na área da Educação até 2017, segundo dados da Plataforma Sucupira (2017), e, desse total, 135 programas são associados na ANPEd.

O balanço crítico do período 2003-2007 levantou 15.418 trabalhos defendidos por discentes nos "programas de pós-graduação stricto sensu em educação, e a análise dos resumos simples e das palavras-chave permitiu selecionar 1.167 teses e dissertações que abordaram o tema Formação de profissionais da educação." (BRZEZINSKI, 2014, p. 13).

Como procedimento metodológico foi organizada uma amostra com 18 programas considerando a abrangência geográfica. Observou-se que cinco dos 18 PPGEs pesquisados mantêm doutorado com teses defendidas durante o período 2003-2007. Dentre as Universidades pesquisadas constatouse que a Pontifícia Universidade Católica de São Paulo (PUC-SP) foi a maior produtora sobre a temática, com 95 trabalhos, que representam 17\% do total. Em seguida, a Universidade Federal do Rio Grande do Sul (UFRGS), com 65 
trabalhos (11\%); a Universidade Federal Fluminense (UFF), com 52 (9\%); e a Universidade de São Paulo (USP), com 51 (9\%). Por regiões, a produção de maior concentração foi a região Sudeste, com 48\% dos trabalhos discentes, porém deve ser observado que essa é a região onde se localiza o maior número de programas e de universidades do País.

Ao observar as categorias de análise, constatou-se que a categoria mais investigada foi o trabalho docente, sendo produzidas $170(30 \%)$ teses e dissertações, seguida pela categoria identidade e profissionalização docente, com 128 (22\%). Considerando-se a ordem decrescente, seguemse as categorias: formação inicial, com 92 (16\%); formação continuada, com 78 (14\%); políticas e propostas de formação de professores, com 76 (13\%); concepções de docência e de formação de professores, com 19 (3\%); e revisão de literatura, com 10 (2\%) (BRZEZINSKI, 2014).

Entre os autores nacionais mais consultados aparecem, em ordem decrescente: Freire, Saviani, Arroyo, Gatti, Brzezinski, Pimenta, André, Candau, Antunes, Mizukami, Ludke, Frigotto, Gadotti e Beisiegel (BRZEZINSK, 2014). Quanto aos autores estrangeiros destacamos os quatro mais consultados: Nóvoa, Perrenoud, Tardif e Piaget (BRZEZINSK, 2014).

Acerca do período de 2008 a 2010, o estudo sobre a produção discente foi materializado em teses e dissertações defendidas nos programas de pósgraduação em educação brasileira, no período de 2008-2010, evidenciando que doutorandos e mestrandos de 17 universidades estudaram a formação de profissionais da educação. Do universo de 9.886 teses e dissertações defendidas nesse período, foram pré-selecionados 1.947, e destas, a partir dos critérios de definição da amostra, foram selecionadas 420. E, em virtude da redução do número de investigadores durante o processo, foram construídos resumos expandidos e analisados 200 trabalhos, contendo 10 teses e 190 dissertações.

As categorias eleitas repetem as da pesquisa do período de 20032007, quais sejam: Concepções de Docência e de Formação de Professores; Políticas e Propostas de Formação de Professores; Formação Inicial; Formação Continuada; Trabalho Docente; Identidade e Profissionalização Docente; e Revisão de Literatura. 
Essas categorias ficaram representadas conforme a Tabela construída pela autora:

Tabela 2 - Teses e dissertações por categoria e ano (2008-2010)

\begin{tabular}{lrrrrrcrcr}
\hline Anos & $\begin{array}{c}\text { Concepçães } \\
\text { de docência e de } \\
\text { formação de } \\
\text { professores }\end{array}$ & $\begin{array}{c}\text { Políticas e } \\
\text { propostas de } \\
\text { formação } \\
\text { de professores }\end{array}$ & $\begin{array}{c}\text { Formação } \\
\text { inicial }\end{array}$ & $\begin{array}{c}\text { Formação } \\
\text { continuada }\end{array}$ & $\begin{array}{c}\text { Trabalho } \\
\text { docente }\end{array}$ & $\begin{array}{c}\text { Identidade } \\
\text { e profissão } \\
\text { docente }\end{array}$ & $\begin{array}{c}\text { Revisão } \\
\text { da }\end{array}$ & $\begin{array}{c}\text { Total } \\
\text { literatura }\end{array}$ \\
\hline 2008 & 7 & 8 & 19 & 18 & 17 & 20 & - & 88 \\
2009 & 6 & 9 & 21 & 5 & 17 & 10 & - & 69 \\
2010 & 2 & 4 & 18 & 2 & 11 & 5 & 1 & 43 \\
\hline Total & 15 & 21 & 58 & 25 & 45 & 35 & 1 & 200 \\
\hline
\end{tabular}

Fonte: Brzezinski (2014).

Comparando com os resultados da pesquisa do período de 2003-2007. a categoria Trabalho docente, que havia sido a mais investigada, ficou com o segundo lugar em 2008-2010. A categoria Formação inicial, que na outra pesquisa estava em segundo, ficou nesse último período como o tema mais pesquisado.

No que diz respeito à amostra das instituições e programas por regiões geográficas, embora sendo substituídas algumas instituições na região Sudeste e Centro-Oeste, não se alteraram as concentrações, ficando a região Sudeste em primeiro, com 29\% das produções, seguida pelas regiões Sul, Centro-Oeste, Nordeste e Norte. O destaque fica para a região Centro-Oeste, que aumentou o número de produções em relação ao período anterior.

Entre os autores nacionais mais consultados aparecem, em ordem decrescente: Freire, Saviani, Libâneo, Veiga, Brzezinski, Demo, Moran, Arroyo, Lüdke, Gatti e Freitas. Quanto aos autores estrangeiros destacamos os quatro mais consultados: Marx, Bourdieu, Foucault e Vygotsky.

Brzezinski (2014), em suas considerações finais, destaca o reconhecimento da relevância da pesquisa sobre a formação de professores, porém enfatiza que os discentes pesquisadores deixam de verticalizar os estudos sobre a formação docente para abarcar os fundamentos epistemológicos, didáticos e metodológicos desta. Ainda, como lacuna a ser superada está a necessidade de descrever com mais riqueza o método, a metodologia e o instrumental utilizado pelos pesquisadores em suas investigações. 


\section{METODOLOGIA PROPOSTA PARA A PESQUISA (2001 A 2016)}

O estado da arte é uma pesquisa que se preocupa com a totalidade da produção de um dado conhecimento. Segundo Romanowski e Ens (2006, p. 39):

estados da arte podem significar uma contribuição importante na constituição do campo teórico de uma área de conhecimento, pois procuram identificar os aportes significativos da construção da teoria e prática pedagógica, apontar as restrições sobre o campo em que se move a pesquisa, as suas lacunas de disseminação, identificar experiências inovadoras investigadas que apontem alternativas de solução para os problemas da prática e reconhecer as contribuições da pesquisa na constituição de propostas na área focalizada.

Neste artigo, tomando por referência de consulta o Portal de periódicos CAPES/MEC (2017), intenta-se responder, nesse recorte proposto, ao que o Brasil tem pesquisado sobre formação de professores nos primeiros 15 anos do século XXI. Trata-se de um questionamento que abrange um grande número de variáveis e que requer a abordagem quantitativa para responder.

A preocupação em organizar os dados quantitativamente e com razoável grau de precisão requer o método estatístico, segundo Gil (2008, p. 17). Com esse método, as informações coletadas são registradas como variáveis determinadas em termos numéricos, configurando uma metodologia favorável para esse tipo de pesquisa.

Os dados foram obtidos por meio de consultas ao Portal de periódicos CAPES/MEC (2017). A pesquisa em periódicos é um procedimento bibliográfico que, de acordo com Gil (2008, p. 50), oferece vantagens por poder cobrir uma maior quantidade de dados, caso desta pesquisa, que se ocupa em abranger alta dispersão de dados entre o tempo e bibliotecas.

Para a coleta e a categorização dos dados, foi organizada uma planilha eletrônica com colunas que demandaram o seguinte: ano de publicação, 
estado em que trabalha o autor instituição em que o pesquisador atua, assunto pesquisado, subtema pesquisado, revista de publicação, aporte teórico, aporte metodológico, biblioteca, autoria e título.

As consultas foram delimitadas pelos filtros on-line disponíveis em cada biblioteca eletrônica. Assim, pesquisaram-se os verbetes "formação docente ou formação de professores", contidos nos títulos dos artigos de cada biblioteca, compreendendo que as pesquisas os tratam como sinônimos; delimitou-se a coleta por cada ano, para evitar equívocos. Também, limitou-se a pesquisas brasileiras, em português, e somente publicações do tipo artigo - a limitação a artigos ocorreu em razão de serem publicações contínuas, considerando a praxe de pesquisadores publicarem em formato de artigo a sua dissertação ou tese.

Somente os artigos que trataram a "formação docente ou formação de professores", em seu sentido amplo, foram selecionados; os artigos que especificaram modalidade de ensino, disciplina e grau de ensino foram descartados; esse critério favorece a rigorosidade dos dados, uma vez que os artigos selecionados não contêm fatores distratores de outros temas.

Dos artigos selecionados, leram-se os resumos de cada um, a fim de coletar informações que os caracterizassem. Ferreira (2002, p. 265) questiona as possibilidades de uma pesquisa mediante a leitura de resumos, contudo afirma que, quando se objetiva a quantificação, a identificação de dados, o mapeamento de produções delimitadas em anos, os locais e as áreas de produção, há "certo conforto para o pesquisador, por lidar com os dados objetivos e concretos."

Os assuntos foram selecionados pela leitura dos resumos em consonância a suas palavras-chave, elencando aquela que mais sintetizou as informações do resumo para representar o trabalho.

Por meio desse procedimento bibliográfico, segundo as delimitações aferidas, foram coletados dados de artigos entre 2001 e 2016 , compreendendo pesquisas no período do primeiro quindênio do século XXI. 


\section{O PERCURSO DESTA PESQUISA E SEUS ACHADOS DE 2001 A 2016}

O primeiro ato desta pesquisa ocorreu pela consulta do tema no Portal de periódicos da CAPES/MEC e pela seleção, que resultou em 1.674 artigos, delimitados no quindênio (período de 15 anos) inicial do século XXI. Aplicando os demais critérios de seleção apontados na metodologia deste estudo, foram separados 537 artigos; logo, do resultado geral da pesquisa, apenas 32,07\% atenderam aos critérios de seleção.

A frequência dessas pesquisas, nesse quindênio, está apresentada no Gráfico 2. O referido gráfico apresenta a variância de produção entre os seis primeiros anos, seguida de um progressivo aumento de pesquisas, alcançando o seu primeiro pico no ano 2009, e o pico máximo no ano 2013. Em seguida, observa-se uma forte queda das produções que quase iguala o período inicial ao final desse quindênio, ou seja, os anos 2001 e 2016, sendo 12 e 13 publicações, respectivamente. $\bigcirc$ pico máximo da quantidade de produções somou 64 pesquisas, o que representa 14,47\% de todo o apanhado.

Gráfico 2 - Frequência de publicações entre 2001 e 2016

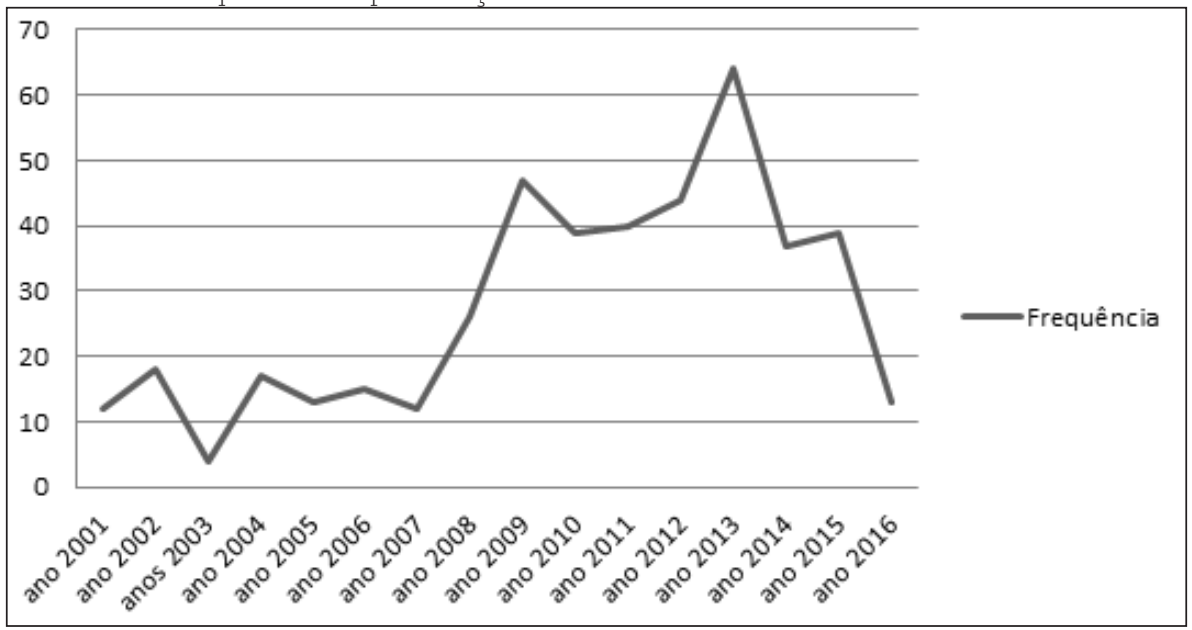

Fonte: os autores. 
No ano de maior quantidade de publicações, os principais assuntos pesquisados foram Políticas, Tecnologias e Educação Especial.

Gráfico 3 apresenta a quantidade de pesquisas no território brasileiro. Os tons mais intensos representam a maior quantidade de produções e as mais tênues representam o contrário. Na apresentação dos dados, no referido gráfico, foram utilizados como critério de corte os Estados que publicaram menos de cinco artigos, a fim de destacar os lugares que mais publicaram.

Gráfico 3 - Pesquisas brasileiras publicadas entre 2001 e 2016

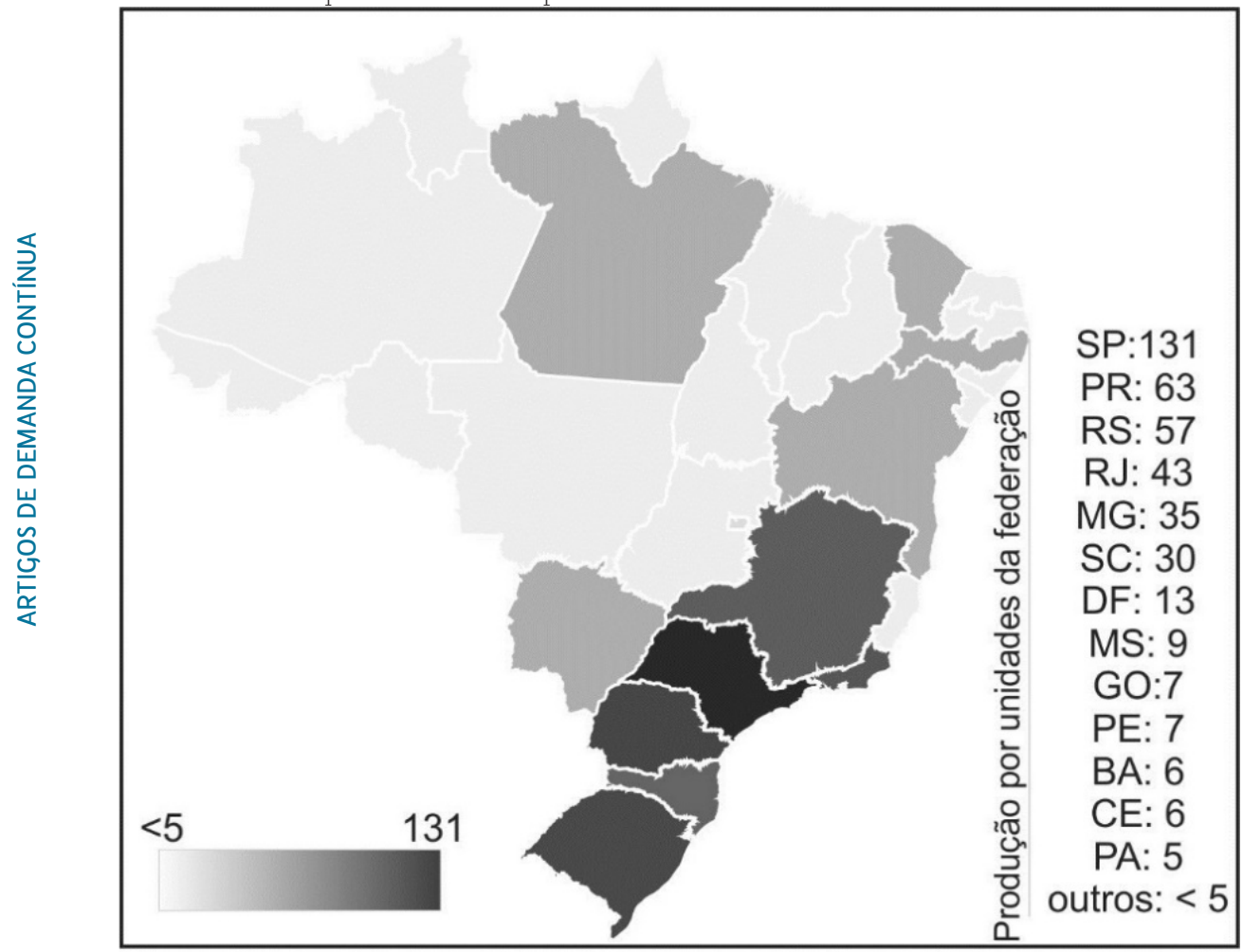

Fonte: os autores.

As consultas revelaram publicações na maioria dos estados brasileiros. A maior quantidade de pesquisas foi produzida pela região Sudeste, com 47,28\% do total de produções, seguida da região Sul, com 33,93\%. Os demais estados produziram menos de $20 \%$ das pesquisas sobre formação de 
professores do País. O Estado de São Paulo é o maior produtor de pesquisas sobre o tema formação de professores, com 29,63\% das produções, seguido do Paraná e do Rio Grande do Sul. Esses resultados podem ser associados à distribuição dos Programas de Pós-Graduação, pois, segundo os dados do Geocapes (2018), a região Sul, seguida da Sudeste, concentra o maior número de Programas e de bolsas de auxílio à Pós-Graduação, e em decorrência disso, maior número de docentes e discentes.

O Gráfico 4 apresenta a produção de pesquisas pelas universidades ou faculdades, utilizando a sigla das instituições para referenciá-las. Para este Gráfico, utilizou-se o critério de corte para instituições com menos de cinco publicações, a fim de aumentar a legibilidade do gráfico, que pretende destacar a maior quantidade de produções.

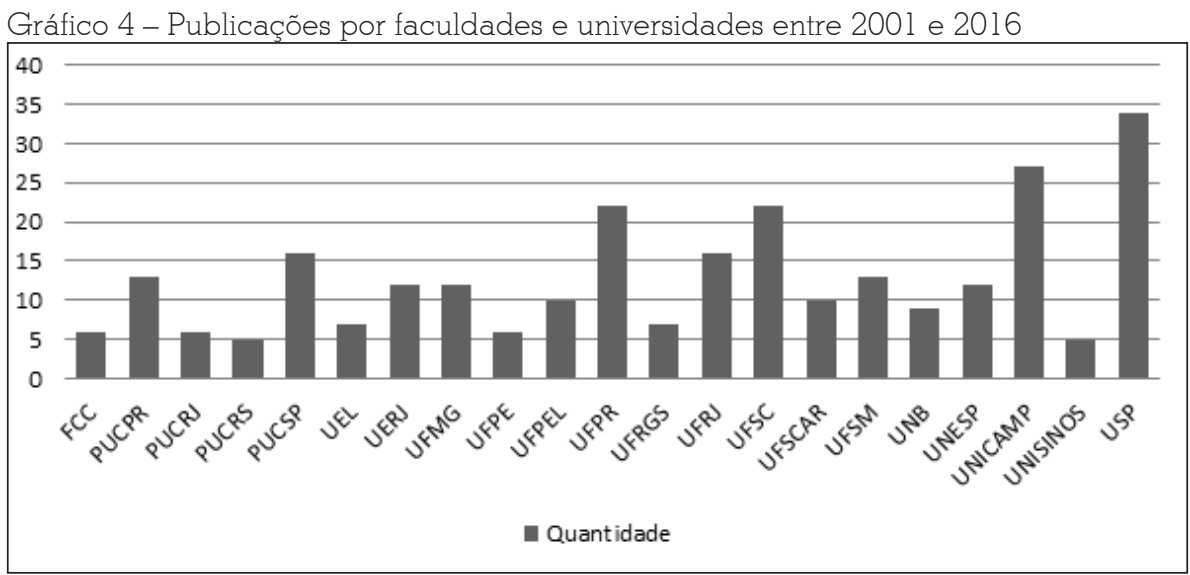

Fonte: os autores.

A USP apresenta a maior quantidade de produções, com 7,29\% das pesquisas nacionais sobre o tema. A Unicamp apresenta a segunda maior quantidade de produção, com 6,10\% das pesquisas nacionais. A UFPR e a UFSC representam, igualmente, 4,97\% das pesquisas nacionais, sendo estas as maiores quantidades da região Sul.

Os principais assuntos das revistas que mais publicaram são: USP, apresenta diversificação de dados, não destacando um assunto; Unicamp, a 
que mais pesquisou sobre políticas e tecnologias; e UFPR, a que mais pesquisou sobre história e educação a distância.

As consultas implicam a formação de professores ou formação docente, que é o tema principal dos artigos; contudo, aparece um subtema que divide os artigos em formação inicial e formação continuada. Assim, 86\% das pesquisas tratam da formação inicial do professor, enquanto os outros 14\% se dedicam à formação continuada do professor.

Referente ao subtema formação continuada, as três universidades que mais o pesquisaram publicaram três trabalhos cada, a saber: UFPR, UFRJ, Unisinos e Unioeste. A revista que mais publicou esse subtema é a Diálogo Educacional, somando sete publicações.

Acerca da formação inicial, essa subtemática foi mais pesquisada por universidades distintas daquelas que tiveram seu foco na formação continuada. Aparecem com maior número de publicações a USP, seguida pela Unicamp e pela UFSC. Porém, a localização dessas universidades continua não extrapolando a região Sul e Sudeste. Estas e as demais universidades que tiveram expressivas publicações sobre a formação inicial são mencionadas no Gráfico 5.

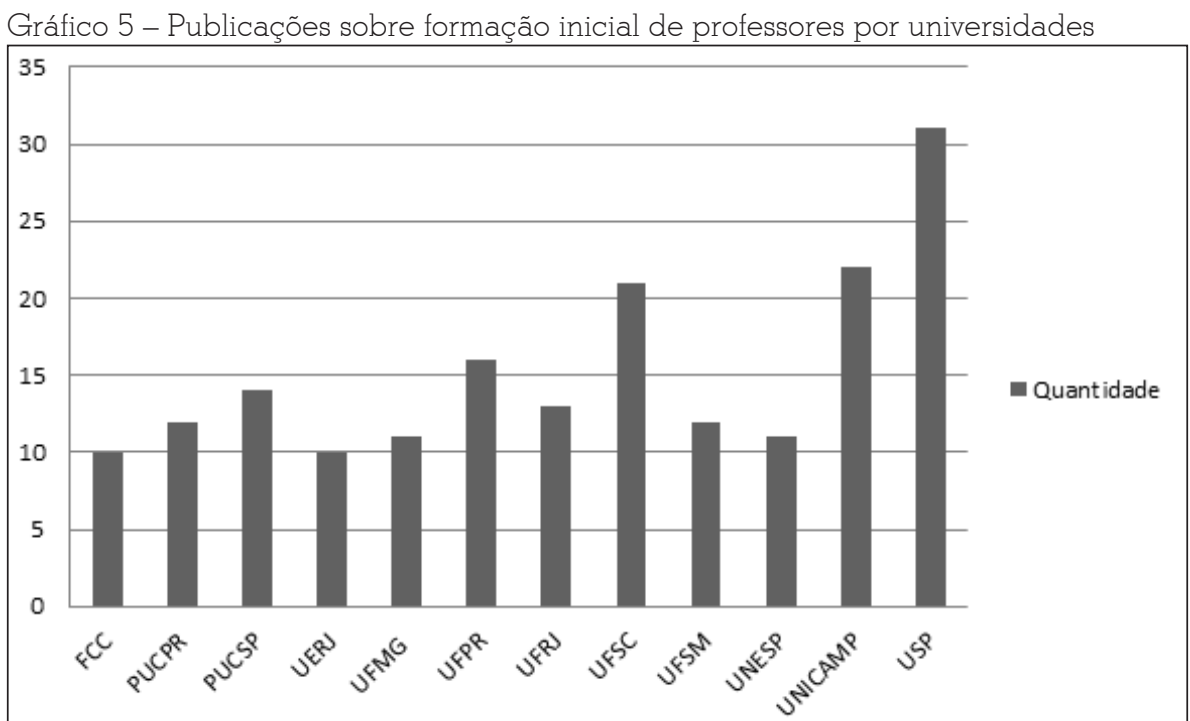

Fonte: os autores. 
$\bigcirc$ assunto de cada artigo é um fator muito relevante, pois é ele que refina o tema e aponta maior rigorosidade ao trabalho. Associado ao tema é possível deduzir o que se tem abordado no quindênio referido. Para evidenciar esses dados, foram necessários uma tabela para apontar os principais assuntos e um gráfico para especificar os resultados quanto a sua quantidade.

A Tabela 3 apresenta os principais assuntos e a quantidade que se soma das consultas para esta pesquisa. Foram excluídos os assuntos com menos de três publicações, a fim de destacar aqueles com maior quantidade de publicações. Os assuntos estão organizados em ordem crescente de número de publicações.

Tabela 3 - Principais assuntos pesquisados entre 2001 e 2016

\begin{tabular}{lclc}
\hline \multicolumn{1}{c}{ Assunto } & Quantidade & \multicolumn{1}{c}{ Assunto } & Quantidade \\
\hline Estética & 3 & Teoria e prática & 6 \\
Experiência & 3 & Interdisciplinaridade & 6 \\
Gestão & 3 & Educação especial & 6 \\
Inovação & 3 & Identidade & 6 \\
Memória & 3 & História de vida & 7 \\
Profissionalização & 4 & Multiculturalismo & 7 \\
Qualidade & 4 & Psicologia & 7 \\
Modelo & 4 & Pesquisa & 8 \\
Saberes docentes & 4 & Currículo & 8 \\
Reflexão & 4 & Estágio & 12 \\
Representações sociais & 4 & Inclusão & 12 \\
Competências & 4 & Avaliação & 13 \\
Didática & 4 & História & 18 \\
Educação do campo & 4 & Educação a distância & 21 \\
Filosofia & 4 & Tecnologias & 25 \\
Gênero e sexualidade & 5 & Políticas & 42 \\
Prática pedagógica & 5 & Outros & 167 \\
\hline Fonte: os autores: & & \\
\hline & & & \\
\hline
\end{tabular}

Fonte: os autores.

Os assuntos apresentados no Gráfico 5 são genéricos, visto que cada um deles aborda várias dimensões. $\bigcirc$ principal assunto refere-se a políticas, o 
qual corresponde a 9,5\% das pesquisas nacionais em relação ao tema. $\bigcirc$ segundo assunto mais abordado é tecnologias, que corresponde a 5,65\% das pesquisas.

As lacunas de assuntos entre as publicações são dados difíceis de se atingir. Para chegar a elas não bastou apenas apontar a menor quantidade de publicações, pois isso apontaria um grande número de assuntos, o que tornaria a informação irrelevante. Assim, para destacar os assuntos que menos são tratados, foram selecionados os trabalhos com a menor quantidade de publicação e que fosse maior do que 1. Esses assuntos, com menor representatividade, são apresentados na Tabela 4 em ordem alfabética.

Tabela 4 - Assuntos menos publicados entre 2001 e 2016

\begin{tabular}{|c|c|c|c|}
\hline Autonomia & Educação superior & Gestão & Paradigmas \\
\hline $\begin{array}{l}\text { Desenvolvimento } \\
\text { profissional }\end{array}$ & Epistemologia & Hábitus & Subjetividade \\
\hline Didática & Estética & Histórico-cultural & Tendências \\
\hline $\begin{array}{l}\text { Diretrizes curri- } \\
\text { culares }\end{array}$ & Ética & Interculturalidade & $\begin{array}{l}\text { Valorização do- } \\
\text { cente }\end{array}$ \\
\hline Discurso & Filosofia da diferença & Movimentos sociais & --- \\
\hline
\end{tabular}

Fonte: os autores.

Com o intuito de evidenciar as fontes que mais publicaram sobre a formação de professores, passamos a apresentar um quadro e um gráfico detalhando essas informações. Assim, o Quadro l apresenta o nome das revistas em ordem alfabética, a instituição a que estão vinculadas, a cidade de origem, o seu respectivo ISSN, respectiva avaliação "qualis CAPES/2015" e a quantidade de publicação sobre o tema.

Quadro 1 - Periódicos com mais de cinco artigos publicados entre 2001 e 2016

\begin{tabular}{|l|l|l|l|l|l|}
\hline \multicolumn{1}{|c|}{ Revista } & \multicolumn{1}{|c|}{ Instituição } & \multicolumn{1}{c|}{ Cidade } & \multicolumn{1}{c|}{ ISSN } & ${ }^{*}$ Qualis & ${ }^{* *}$ Qt. \\
\hline Educar & UFPR & Curitiba & $0104-4060$ & Al & 43 \\
\hline Educação & UFSM & Santa Maria & $1984-6444$ & Bl & 41 \\
\hline Diálogo Educacional & PUCPR & Curitiba & $1981-416 \mathrm{X}$ & A2 & 39 \\
\hline
\end{tabular}




\begin{tabular}{|c|c|c|c|c|c|}
\hline Educação em Revista & UFMG & $\begin{array}{l}\text { Belo Hori- } \\
\text { zonte }\end{array}$ & 1982-6621 & A2 & 27 \\
\hline $\begin{array}{l}\text { Educação \& Socie- } \\
\text { dade }\end{array}$ & Unicamp & Campinas & $1678-4626$ & $\mathrm{Al}$ & 26 \\
\hline Educação e Pesquisa & USP & São Paulo & $1678-4634$ & Al & 26 \\
\hline $\begin{array}{l}\text { Cadernos de Pes- } \\
\text { quisa }\end{array}$ & FCC & São Paulo & 1980-5314 & B2 & 18 \\
\hline Ensaio & CESGRANRIO & $\begin{array}{l}\text { Rio de } \\
\text { Janeiro }\end{array}$ & $1809-4465$ & $\mathrm{Al}$ & 16 \\
\hline $\begin{array}{l}\text { Revista Brasileira de } \\
\text { Educação }\end{array}$ & ANPED & $\begin{array}{l}\text { Rio de } \\
\text { Janeiro }\end{array}$ & $1413-2478$ & $\mathrm{Bl}$ & 16 \\
\hline E-Curriculum & PUCSP & São Paulo & $1809-3876$ & A2 & 10 \\
\hline $\begin{array}{l}\text { Revista Eletrônica de } \\
\text { Educação }\end{array}$ & UFSCAR & São Carlos & 1982-7199 & A2 & 10 \\
\hline Pro-posições & Unicamp & Campinas & $1980-6248$ & $\mathrm{Al}$ & 9 \\
\hline ECCOS & Uninove & São Paulo & $1983-9278$ & $\mathrm{Bl}$ & 8 \\
\hline $\begin{array}{l}\text { Educação Temática } \\
\text { Digital }\end{array}$ & Unicamp & Campinas & 1676-2592 & $\mathrm{Bl}$ & 8 \\
\hline Cadernos Cedes & Unicamp & Campinas & $0101-3262$ & $\mathrm{Al}$ & 7 \\
\hline $\begin{array}{l}\text { Educação \& Reali- } \\
\text { dade }\end{array}$ & UFRGS & Porto Alegre & $2175-6236$ & Al & 7 \\
\hline História Educação & UFRGS & Porto Alegre & $2236-3459$ & A2 & 7 \\
\hline Nuances & UNESP & São Paulo & $2236-0441$ & A2 & 7 \\
\hline $\begin{array}{l}\text { Psicologia Escola e } \\
\text { Educacional }\end{array}$ & ABRAPEE & São Paulo & 2175-3539 & $\mathrm{Bl}$ & 7 \\
\hline Avaliação & Unicamp & Campinas & $1414-4077$ & A2 & 6 \\
\hline Conjectura & UCS & $\begin{array}{l}\text { Caxias do } \\
\text { Sul }\end{array}$ & $2178-4612$ & B2 & 6 \\
\hline Espaço do Currículo & UFPB & João Pessoa & 1983-1579 & $\mathrm{Bl}$ & 6 \\
\hline Ciência \& Educação & Unesp & Bauru & 1980-850X & $\mathrm{Al}$ & 5 \\
\hline Outros & -- & -- & -- & -- & 262 \\
\hline
\end{tabular}

Fonte: os autores.

Notas: *Qualis Capes (Disponível em: <https://sucupira.capes.gov.br/sucupira/ public/consultas/coleta/veiculoPublicacaoQualis/listaConsultaGeralPeriodicos. jsf $>) .{ }^{*}$ Quantidade.

A Revista Educar, da UFPR no Paraná, tem a maior quantidade de publicações, corresponde a 9,72\% das publicações nacionais sobre o tema, 
seguida da Revista Educação, da UFSM do Rio Grande do Sul, que corresponde a 9,27\% das publicações nacionais.

Gráfico 6 apresenta os pesquisadores que mais publicaram sobre o tema formação de professores.

Gráfico 6 - Autores que mais publicaram entre 2001 e 2016

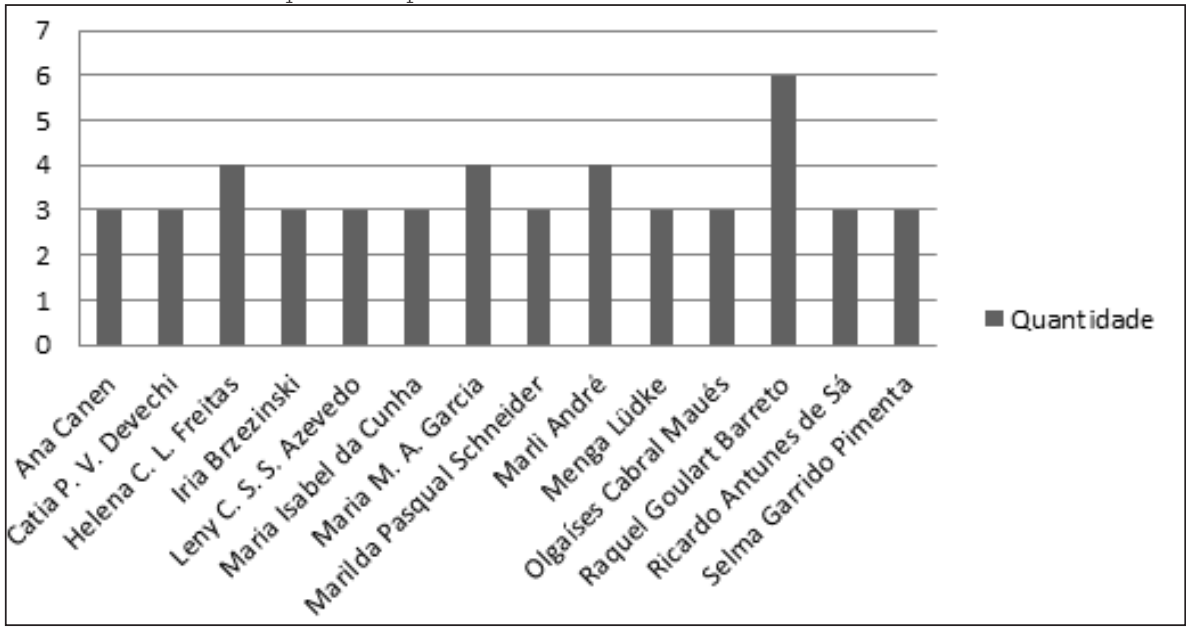

Fonte: os autores.

As consultas apontam um grande número de autores; entre os que mais publicaram sobre o tema formação de professores computam a média de três publicações. A autora Doutora Raquel Goulart Barreto, que atua na Universidade Estadual do Rio de Janeiro (UFRJ), apresenta a maior quantidade de publicações desta investigação, correspondente a 1,35\% das publicações. É importante relembrar que essa conclusão considerou os artigos dentro do recorte metodológico e vinculados ao Portal de periódicos CAPES no referido período de coleta de dados.

Os assuntos mais pesquisados pelas autoras que mais publicaram são: Raquel Goulart Barreto, que mais pesquisou sobre tecnologias; Helena C. L. Freitas, sobre educação a distância; Maria M. A. Garcia, sobre ética; e Marli André, sobre políticas; mais uma vez lembrando que tais resultados estão delimitados pelos critérios apontados na metodologia desta pesquisa. 
Cabe ressaltar que as produções desses pesquisadores sobre formação de professores, evidenciadas no Gráfico 6, bem como dos autores que não constam nele, não se resumem ao que foi exposto. Portanto, o rigor dos resultados é razoável para os critérios estabelecidos para consulta e seleção desta pesquisa.

De outras informações, que é parte do objetivo neste trabalho, cabe ressaltar também, que a falta de algumas informações nos resumos tornou duas categorias de dados inconsistentes, são as categorias de metodologia e fundamentação teórica. Sobre a fundamentação teórica, apenas 5,42\% dos artigos apresentaram essa informação nos resumos, apontando Paulo Freire e Michel Foucault como os principais autores utilizados nas pesquisas, seguidos por Pierre Bourdieu e Lev Vygotsky. A respeito da metodologia, 21,94\% dos artigos apresentaram alguma informação metodológica explicitamente, ainda assim com algumas divergências teóricas; ao que se pode indicar a entrevista como principal procedimento de coleta de dados, abrangendo 4,29\% de todos os dados desta pesquisa.

Acerca das fontes de informação, a bibliográfica é a mais utilizada, abrangendo $4,07 \%$ de toda a pesquisa. $\bigcirc$ estudo de caso é a metodologia mais utilizada, correspondendo a 2,94\% de todos os dados. Os dados podem apontar o que mais se utiliza na metodologia e coleta de dados, porém são inconsistentes por derivarem da menor parte de resumos consultados. Um número ínfimo de artigos apresentou alguma alusão ao método de pesquisa e principais referências teóricas no resumo.

\section{CONSIDERAÇÕES FINAIS}

Este artigo, ao tomar como referência de consulta o Portal de periódicos da CAPES, se propôs a jogar luzes naquilo que o Brasil tem pesquisado sobre formação de professores nos primeiros 15 anos do século XXI. Os dados anunciados por meio do censo realizado pelo Diretório dos Grupos de Pesquisa no Brasil/CNPq, dos anos 2001 a 2016, de forma geral 
e preliminar, apontaram um crescimento vertiginoso nas produções, sejam decorrentes da formação e/ou da pesquisa.

No estudo de Brzezinsk (2006), que abrangeu o período de 19972002, comparando com o Estado do Conhecimento sobre o tema do período 1990-1996, realizado por André (2002), aponta para uma mudança do eixo nos objetos pesquisados, pois a produção discente sobre a categoria Trabalho Docente foi muito maior do que a que se refere à Formação Inicial, categoria absolutamente predominante no estudo anterior. Essa mesma categoria se mantém predominante no estudo de Brzezinsk (2014), que abarcou o período de 2008-2010, sendo seguidos pelo Trabalho Docente, Identidade e Profissão Docente, Formação Continuada, Políticas e Propostas de Formação de Professores e Concepções de Docência e formação de Professores.

Dos 1.674 artigos consultados, que submetidos a critérios de seleção resultaram em 442 artigos, foi possível perceber que as produções sobre a formação de professores têm uma evidente oscilação de uma baixa quantidade de produção nos primeiros anos, seguido de um agudo aumento produtivo que atinge o seu pico em 2013, havendo, a seguir, um forte decrescimento a partir do próximo ano, 2014, indicando uma perda maior do que 20\% do pico de produção.

Estado brasileiro que mais pesquisa esse tema é São Paulo, principalmente na USP, repercutindo na região Sudeste como a que mais desenvolve esse tema no Brasil, com 47,28\% das publicações nacionais. A quantidade expressiva de pesquisadores apontadas no censo do Diretório dos Grupos de Pesquisa no Brasil/CNPq, já apontava esse mesmo Estado, embora em um critério de número de pesquisadores englobando todas as áreas, portanto confirmando essa tendência. Esse dado, da concentração da produção na região Sudeste, também é ratificado pelas pesquisas de Brzezinski (2006, 2014).

tema da pesquisa se subdivide em dois: formação inicial (mais pesquisado) e formação continuada do professor. Ainda, para este tema, os três principais assuntos pesquisados foram Políticas, Tecnologias e Educação a distância. 
As três revistas que mais publicam o tema supracitado são: Educar em Revista (UFPR), Revista Educação (UFSM) e Revista Diálogo Educacional (PUCPR). A autora Doutora Raquel Goulart Barreto, atuante na Universidade do Estado do Rio de Janeiro, é a que mais publicou sobre o tema neste quindênio.

Alguns resumos foram elaborados com falta de informação. Segundo Koller, Couto e Hohendorff (2014, p. 93), um resumo deve apresentar: objetivo, método, resultados e considerações finais. Especificamente sobre o método, deve conter: descrição da realização, características da pesquisa, multimétodos; descrição dos participantes do estudo, dos instrumentos, testes, escalas, procedimentos de coleta e análise de dados.

Assim, a fundamentação teórica e a metodologia são categorias que apresentam inconsistência de dados pela defasagem de informações. No entanto, daqueles que citam seus referenciais bibliográficos, os autores que mais se destacam é Paulo Freire e Michel Foucault. Comparando com o Estado da Arte de 1997-2010, no que tange aos autores mais citados, aparece de forma unânime como o mais citado Paulo Freire. No que se refere a metodologias, do período 2001-2016, a entrevista é mais utilizada para coletar dados. Um número ínfimo de resumos anuncia o método utilizado.

De forma geral, tanto nas pesquisas de 1997 a 2010 de Brzezinski e desta última de 2001-2016, acerca dos resumos é possível afirmar a falta de informações, como principais referências bibliográficas, e/ou metodologia, e/ ou método e/ou assuntos/temas, e/ou natureza de pesquisa e/ou distribuição geográfica. Do assunto, há diminutas pesquisas sobre autonomia, experiência, gestão, subjetividade, formação em serviço e emancipação. Dos métodos, demanda consenso em indicar o método do trabalho nos resumos para caracterizar a pesquisa e especificar (ou detalhar) a metodologia utilizada. Da natureza de pesquisa, não há indicações de pesquisas quantitativas, constituindo uma lacuna nesse tema. E, acerca da distribuição geográfica das produções, constata-se a falta e/ou pouca publicação de pesquisas sobre formação de professores nas regiões Norte, Centro-Oeste e Nordeste.

Por fim, estima-se que este trabalho sirva de consulta para outras pesquisas, a fim de fecundar a produção acadêmica com este recorte dado 
como "estado da arte" do precioso tema que é a formação de professores, bem como incitar outras pesquisas de similar objetivo, abrangendo o tema com especificação de disciplinas e modalidades de ensino, que foram excluídos deste trabalho; também, a ampliação desta pesquisa para outros produtos além do artigo, como livros, teses e dissertações.

\section{REFERÊNCIAS}

ANDRÉ, M. E. D. A. de (Org.). Formação de professores no Brasil (19901998). Brasília, DF: MEC/Inep/Comped, 2002.

ANPED. GTO8 - Formação de professores. Disponível em: <http://www. ANPEd.org.br/grupos-de-trabalho/gt08-forma\%C3\%A7\%C3\%A3o-de-professores $>$. Acesso em: 23 mar. 2017.

BRZEZINSKI, I. (Org.) Formação de profissionais da educação (1997-2002). Brasília, DF: MEC/Inep, 2006.

BRZEZINSKI, I. (Org.) Formação de profissionais da educação (2003-2010). Brasília, DF: MEC/Inep, 2014.

DIRETÓRIOS DOS GRUPOS DE PESQUISA NO BRASIL. Séries Históricas. Disponível em: <http://lattes.cnpq.br/web/dgp/sobre>. Acesso em: 28 fev. 2017.

GEOCAPES. Concessão de bolsas de pós-graduação da CAPES no Brasil. Disponível em: <https://geocapes.capes.gov.br/geocapes/>. Acesso em: 07 ago. 2018.

FERREIRA, N. S. de A. As pesquisas denominadas "estado da arte". Educação \& Sociedade, São Paulo, ano 23, n. 79, p. 257-272, ago. 2002.

GIL, A. C. Métodos e técnicas de pesquisa social. 6. ed. São Paulo: Atlas, 2008.

KOlLER, S. H.; COUTO, M. C. P. P.; HOHENDORFF, J. V. Métodos de pesquisa: manual de produção científica. Porto Alegre: Penso, 2014. 
PLATAFORMA SUCUPIRA. Cursos avaliados. Disponível em: <https://sucupira.capes.gov.br/sucupira/public/consultas/coleta/programa/quantitativos/ quantitativoAreaAvaliacao.xhtml>. Acesso em: 24 mar. 2017.

PORTAL DE PERIÓDICOS DA CAPES/MEC. Disponível em: < http://www. periodicos.capes.gov.br/?option $=$ com_pfaq\&controller $=$ Show\&view $=$ pfaqsho $\mathrm{w} \& \mathrm{mn}=72 \&$ smn $=85 \&$ limitstart=4>. Acesso em: 02 jun. 2017.

ROMANOWSKI, J. P.; ENS, R. T. As pesquisas denominadas do tipo "Estado da arte" em educação. Diálogo Educacional, Curitiba, v. 6, n. 19, p. 37-50, dez. 2006.

Recebido em 17 maio de 2018 Aceito em 09 de agosto de 2018

Endereços para correspondência: Rua Dr. Jose Pallu, 451, apartamento 12 , 81020-050, Curitiba, Paraná, Brasil; prof_jerry@hotmail.com 
